\title{
Comparison of low-molecular-weight organic acids and ethylenediaminetetraacetic acid to enhance phytoextraction of heavy metals by maize
}

\begin{abstract}
We compared acetic, ascorbic, and oxalic acids with ethylenediaminetetraacetic acid (EDTA) to enhance phytoextraction of nickel $(\mathrm{Ni})$, manganese $(\mathrm{Mn})$, zinc $(\mathrm{Zn})$, copper $(\mathrm{Cu})$, cadmium $(\mathrm{Cd})$, and lead $(\mathrm{Pb})$ by maize. Except ascorbic acid, acids significantly $(\mathrm{P}<0.05)$ decreased shoot dry weight with maximum (5.60 g pot-1) recorded with ascorbic acid and minimum with oxalic acid (4.06 g pot-1). Maximum ammonium bicarbonate-diethylenetriaminepenta acetic acid (AB-DTPA)-extractable nickel (19.94 mg kg-1) was recorded with EDTA and it was minimum $(10.57 \mathrm{mg} \mathrm{kg}-1)$ with oxalic acid. The EDTA significantly $(\mathrm{P}<0.05)$ increased AB-DTPA-extractable lead while other acids decreased it. Except acetic acid, other acids significantly $(\mathrm{P}<0.05)$ increased $\mathrm{Ni}$ and $\mathrm{Zn}$ concentration in shoots with maximum $\mathrm{Ni}$ (9.22 mg kg-1) and Zn (37.40 mg kg-1) with EDTA.
\end{abstract}

Keyword: Cadmium; Chelant-assisted phytoextraction; Copper; Lead; Maize growth; Manganese; Nickel; Zinc 